\title{
Shaking Table Test of a New Type Insulation Decorative Block Wall under Out-of-Plane Loading
}

\author{
Jian Wu $\mathbb{D}^{1,2}$ Yuan Yuan Lv ${ }^{1},{ }^{1}$ Shuai Shuai Yin $\mathbb{D D}^{1}$ and Qi Wang $\mathbb{D}^{3}$ \\ ${ }^{1}$ Shaanxi Key Laboratory of Safety and Durability of Concrete Structures, Xijing University, Xi'an 710123, China \\ ${ }^{2}$ The Youth Innovation Team of Shaanxi Universities, Xi'an 710123, China \\ ${ }^{3}$ Zhejiang Guang'an Building Fire Inspection Co., Ltd., Hangzhou 310000, China
}

Correspondence should be addressed to Jian Wu; wujian2085@126.com

Received 29 July 2021; Revised 10 January 2022; Accepted 11 January 2022; Published 3 February 2022

Academic Editor: Kang Shao-Bo

Copyright $(2022$ Jian Wu et al. This is an open access article distributed under the Creative Commons Attribution License, which permits unrestricted use, distribution, and reproduction in any medium, provided the original work is properly cited.

\begin{abstract}
In order to solve the problems of complex construction, poor weather resistance, and environmental pollution of conventional thermal insulation materials, this paper introduces a new type of insulation decorative block (IDB) filled with insulation materials. Different anchoring methods were adopted to study the influence of anchor bolts on the out-of-plane mechanical properties of IDB walls. The test results revealed that the anchor bolts could effectively prevent the appearance and development of cracks in the specimens. With the increase of anchor bolts, the acceleration and displacement of the IDB walls decreased. Compared to rectangular arrangement, the staggered pattern of anchor bolts could reduce the relative displacement and acceleration. The structural calculation of IDB walls was carried out to determine the number of anchor bolts at different heights, and design suggestions were given to improve the performance of IDB walls. The analysis and test results indicated that the IDB is suitable for application in engineering structures.
\end{abstract}

\section{Introduction}

Nowadays, one of the problems that must be solved is how to reduce the emissions by reducing the amount of energy consumed in economic development. Based on the evaluation of energy emissions in China, the building energy consumption accounts for about $30-40 \%$ of the total energy consumption, and the trend continues to rise [1]. The maintenance components of the buildings which are in contact with the outside air, such as windows, doors, floors, and walls, are the primary reason for the energy consumption of buildings. Among these maintenance components, the walls have the largest contact area with the outdoor air, thus having the greatest impact on the building energy consumption [2]. Therefore, it is essential to take wall insulation measures to achieve the goal of the building energy saving and reduce the energy consumption of the external wall.

Thermal insulation materials are divided into organic (e.g., extruded polystyrene (XPS) and expanded polystyrene (EPS)) and inorganic materials (hydrophobic expanded perlite (HEP)). The engineering application of XPS and EPS, as organic materials, is affected by the moisture content and high temperature: (1) the heat transfer coefficient increases with the increase of water content [3-5]; (2) the flammability of materials threatens the safety of structures [6-8]. The high temperature resistance of HEP, as an inorganic material, is relatively stable, while the thermal transfer coefficient is high due to the strong water absorption capacity. These conventional insulation materials could be used as additives in composite materials [9-12] or directly used as external thermal insulation materials of the buildings. When these insulation materials are directly used as building envelope components, structural measures and moisture control components should be proposed to improve the waterproof and fireproof properties of the materials during the construction process [13-15], which increases the construction cost and construction period. In order to deal with the defects of these conventional insulation materials in engineering application, the research on the building insulation materials should be strengthened. 
A new type of thermal insulation blocks, which have high void ratio, is developed and used as the external walls of building [16-18]. The high void ratio of insulation block is helpful to reduce the dead weight and heat transfer coefficient; however, the compressive strength will be adversely affected due to the decrease of compression area. Moreover, the reinforced concrete shear walls are generally used as the external walls of high-rise buildings, indicating that it is impossible to apply the thermal insulation blocks directly. Thus, masonry veneer walls are gradually used in modern building construction. Masonry veneer walls, which consist of external masonry walls separated from the structural backing systems, are connected to the structural components using different types of ties to resist out-of-plane loads [19] and could provide the buildings with decoration and with barriers to moisture wind penetration but do not contribute to the structural resistance [20]. Desai et al. [21] studied the out-of-plane seismic properties of brick veneer wall systems in medium-rise buildings and developed analytical models of structural backing systems and masonry veneer walls. Reneckis et al. [22] described the out-of-plane performance of brick veneer walls on wood frame, and the installation methods, stiffness, and strength were found to significantly affect the seismic performance of veneer walls. Memari et al. [23] evaluated the influence of corrosion of conventional metal anchors on lateral forces, and the performances of corrosion resistant steel ties and conventional ties were compared. Marziale et al. [24] investigated the in-plane coupling between the veneer walls and concrete shear walls, and the optimum location of isolation joint was given to minimize the rocking behavior. These papers provide a reference for the study of mechanical properties of masonry veneer walls; however, the out-of-plane dynamic performance of the walls made of insulation filled masonry blocks is rarely addressed.

This paper presents the results of out-of-plane shaking table test of four full-scale specimens, which are divided by the number and arrangement modes of anchor bolts between the masonry veneer walls and backup framing (reinforced concrete walls): AB0 has no anchor bolts, AB2 is strengthened by two anchor bolts per square meter, and AB4-1 and AB4-2 are strengthened by four anchor bolts per square meter with different arrangement modes.

The structure of this paper is as follows: Firstly, the materials and experimental program, such as the dimension of the IDB, construction of specimens, arrangement of anchor bolts, and test setup, are introduced. Secondly, the mechanical tests are carried out, and the mechanical performance of specimens is obtained and analyzed, e.g., the failure pattern, development of cracks, frequency, acceleration, displacement of the specimens, and relative displacement between the IDB wall and shear wall. Finally, the reaction of IDB walls under wind load and seismic load is calculated, and design recommendations are proposed to improve the application of IDB in engineering.

\section{Experimental Program}

2.1. Masonry Materials. The block is made of shale and sawdust, in which the sawdust could produce a large amount of microporous inside the material, as shown in Figure 1.
The IDB is filled with conventional composite thermal insulation materials, such as XPS, EPS, and HEP, so as to achieve insulation purposes. The dimensions of the IDB are $498 \mathrm{~mm} \times 120 \mathrm{~mm} \times 248 \mathrm{~mm}$ (length $\times$ width $\times$ height), as shown in Figure 2. The density and compressive strength of the IDB are about $500 \mathrm{~kg} / \mathrm{m}^{3}$ and $2.0 \mathrm{MPa}$, respectively.

The content of mortar is cement, fly ash, sand, polymer emulsion powder, and water retaining agent. The mechanical and physical characteristics of mortar are shown in Table 1.

The anchor bolts are used to ensure the bond strength between the IDB wall and the external wall of buildings. The diameter of anchor bolt is $10 \mathrm{~mm}$, and tensile strength is $0.5 \mathrm{MPa}$. The length of the anchor bolt fixed into the reinforced concrete shear wall should not be less than $50 \mathrm{~mm}$.

2.2. Construction of Specimens. In this paper, four full-scale specimens are tested under out-of-plane dynamic loadings. The specimens are composed of ground beam, shear wall, mortar layer, and IDB walls, as shown in Figure 3.

The ground beam is used to fix the specimen on the shaking table, and the shear wall is constructed to simulate the exterior wall of the high-rise building. Materials of leveling blanket and mortar layer are both masonry mortar. The mortar layer is used to strengthen the bond between the shear wall and IDB wall. The thickness of leveling blanket, mortar layer, and mortar joint is $1-2 \mathrm{~mm}, 10 \mathrm{~mm}$, and $1 \mathrm{~mm}$, respectively.

The construction process of the specimens could be seen in Figure 4.

2.3. The Arrangement of Anchor Bolt. In order to study the influence of number and distribution of anchor bolts on the out-of-plane seismic response of the specimen, the experimental program consists of four specimens, in which one specimen has no anchor bolts, one specimen has two anchor bolts per square meter, and two specimens have four anchor bolts per unit area with different arrangement modes of anchor bolts, as shown in Figure 5. The IDB is made of sintered materials, and its brittle failure characteristics are obvious. If the anchor bolts are directly drilled on the IDB, the safety of IDB wall may be affected due to the damage caused by the drilling process.

\section{Testing Procedure and Measurements}

3.1. Test Setup. The performance parameters of the shaking table are shown in Table 2. The digital control system of shaking table (469D) consists of signal control of hydraulic servo system, sequence control of system procedure, and system security protection control, as shown in Figure 6.

The experiments were carried out according to Chinese code GB 50011-2010 [25]. For the normal operation of the test, the out-of-plane loading of the specimen is performed along the $x$ direction.

In order to obtain the displacement and acceleration of the wall during the loading process, acceleration sensor and 


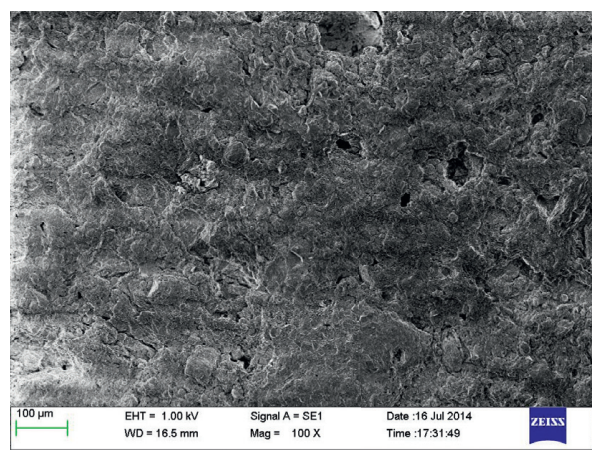

(a)

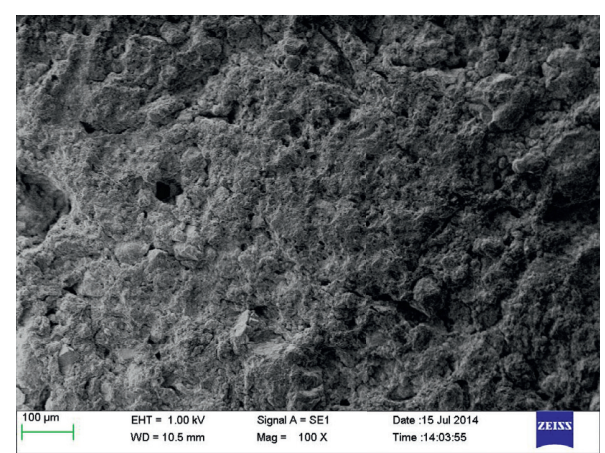

(b)

Figure 1: SEM graphs of sample. (a) Sintering shale sample. (b) Sintering shale sample with 6\% sawdust.

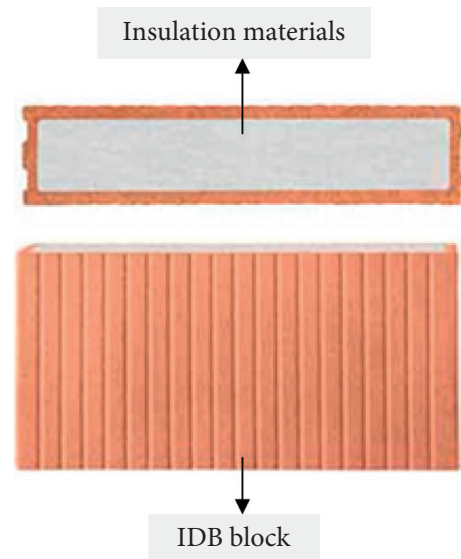

(a)

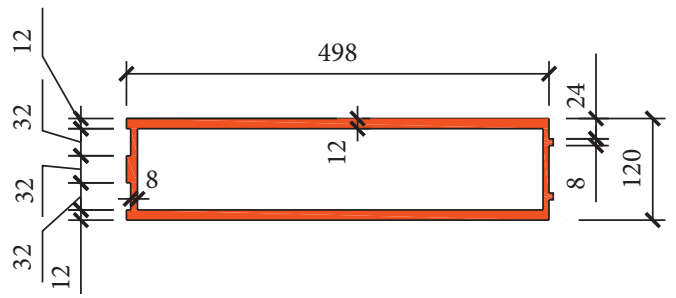

(b)

Figure 2: Introduction of IDB. (a) Components of IDB. (b) Dimensions of IDB.

TABle 1: Performance parameters of mortar.

\begin{tabular}{lccc}
\hline Bond strength $\left(\mathrm{N} / \mathrm{mm}^{2}\right)$ & Compressive strength $\left(\mathrm{N} / \mathrm{mm}^{2}\right)$ & Flexural strength $\left(\mathrm{N} / \mathrm{mm}^{2}\right)$ & Density $\left(\mathrm{kg} / \mathrm{m}^{3}\right)$ \\
\hline 0.1 & 15 & 12 & 1800 \\
\hline
\end{tabular}
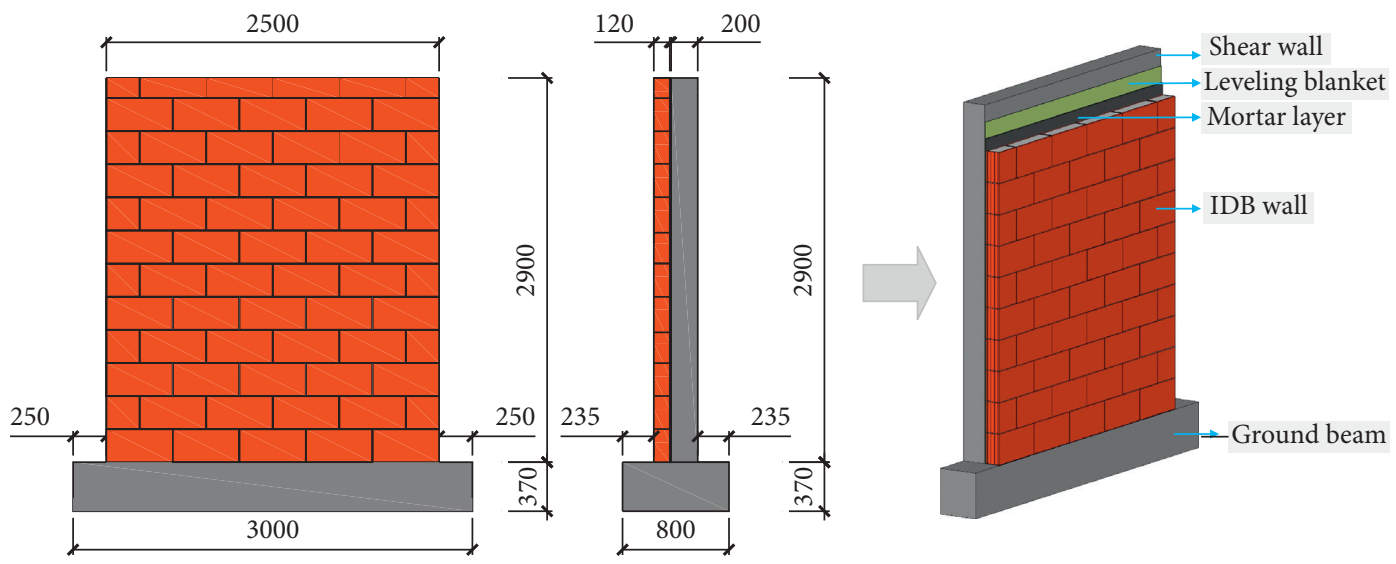

FIgURE 3: Dimensions of the specimens. 


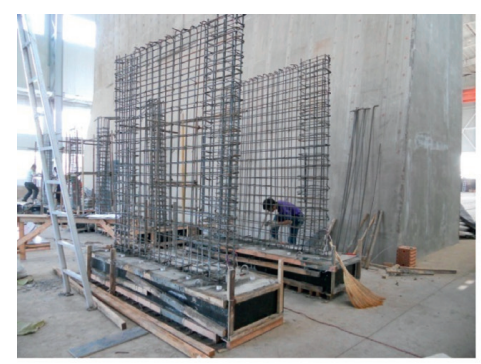

Assembling reinforcement of shear wall

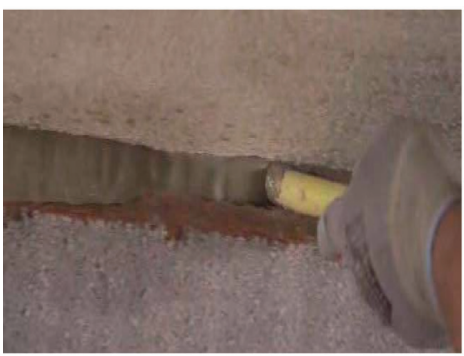

Grouting

M

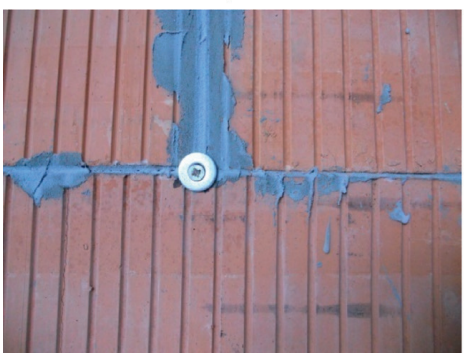

Anchor bolt

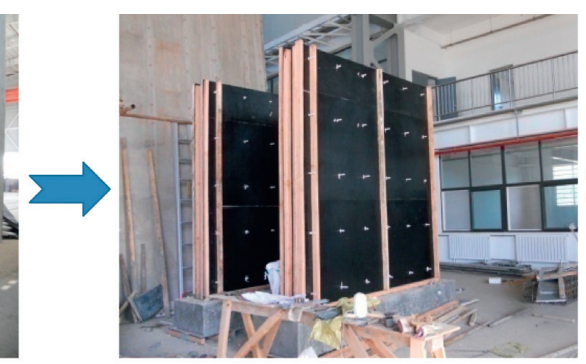

Shuttering installation

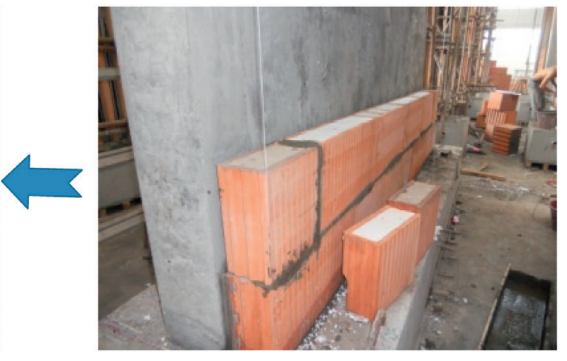

Construction process

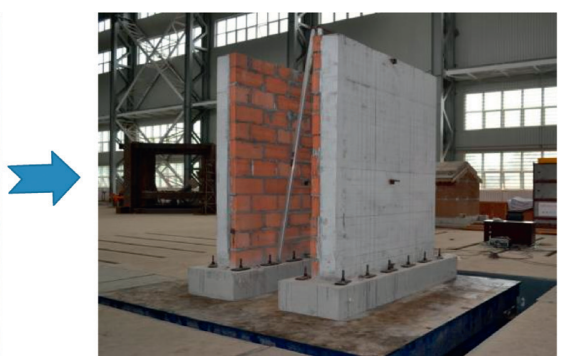

IDB wall

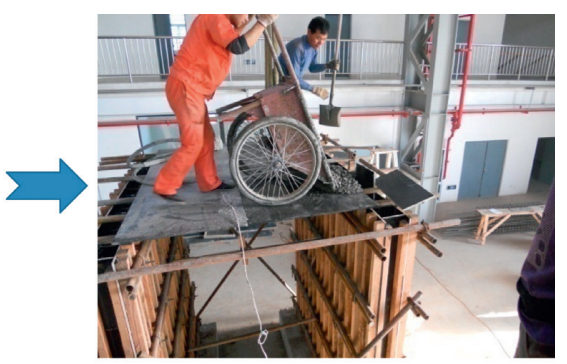

Pouring concrete
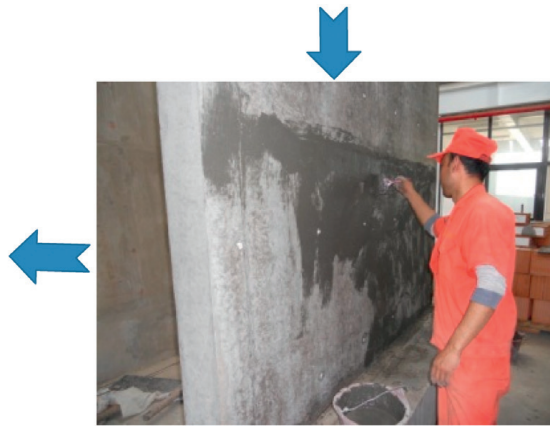

Wall surface treatment

FIGURE 4: Construction process of specimens.

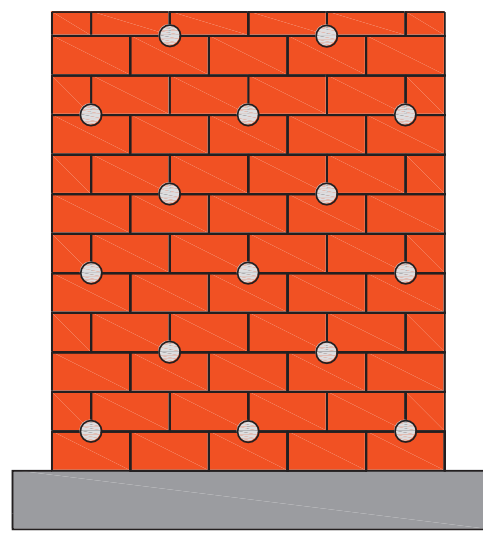

Anchor bolt

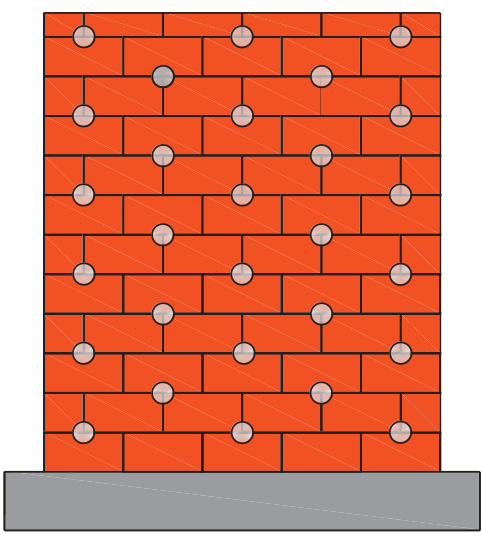

Anchor bolt

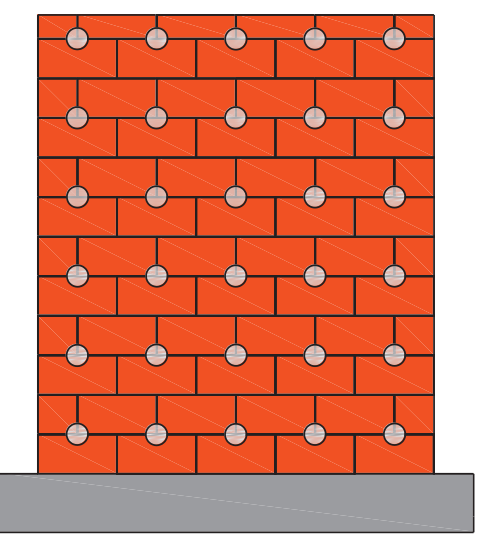

Anchor bolt

(a)

(b)

(c)

FIGURE 5: The arrangement of anchor bolts. (a) AB2. (b) AB4-1. (c) AB4-2. 
TABLE 2: Technical parameters of shaking table.

\begin{tabular}{lc}
\hline Performance of shaking table & Parameter value \\
\hline The dimensions of the table $(\mathrm{m})$ & $4.1 \times 4.1$ \\
Maximum weight of the specimen $(\mathrm{t})$ & 20 \\
Maximum eccentricity $(\mathrm{m})$ & $\geq 0.6$ \\
Frequency $(\mathrm{Hz})$ & $0.1-50$ \\
& $x$ direction: \pm 0.15 \\
Maximum displacement $(\mathrm{m})$ & $y$ direction: \pm 0.25 \\
& $z$ direction: \pm 0.10 \\
\hline & $x$ direction: \pm 0.100 \\
Maximum speed $(\mathrm{m} / \mathrm{s})$ & $y$ direction: \pm 0.125 \\
& $z$ direction: \pm 0.080 \\
\hline & $x$ direction: \pm 15 \\
Maximum acceleration $\left(\mathrm{m} / \mathrm{s}^{2}\right)$ & $y$ direction: \pm 10 \\
& $z$ direction: \pm 10 \\
\hline Maximum overturning $\mathrm{moment}(\mathrm{kN} \cdot \mathrm{m})$ & 300 \\
Maximum eccentric moment $(\mathrm{kN} \cdot \mathrm{m})$ & 800 \\
\hline
\end{tabular}

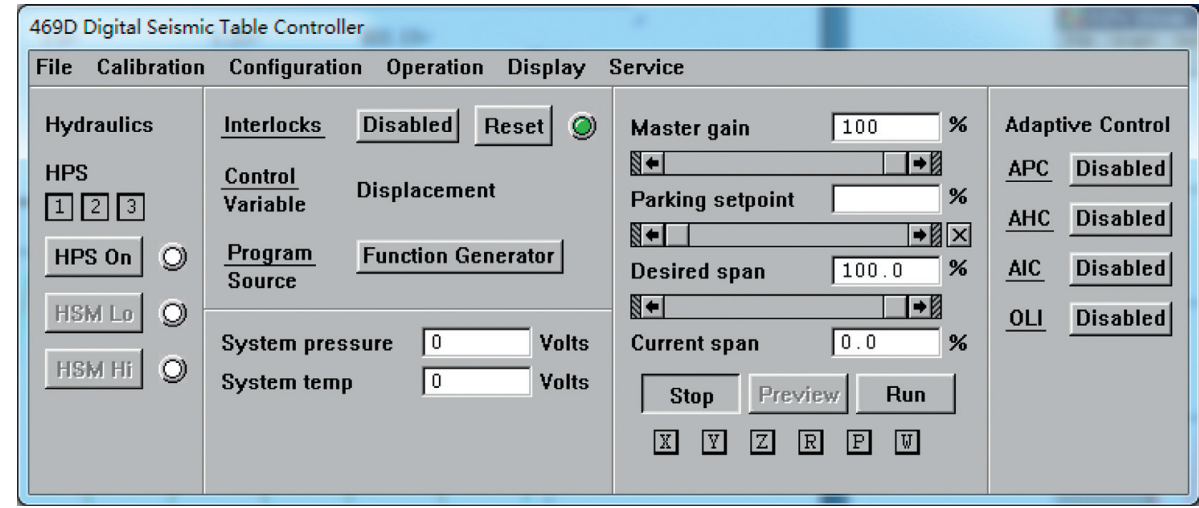

FiguRE 6: Shaking table.

displacement sensor are arranged on the specimens, as shown in Figure 7. The measure range and sensitivity of the acceleration sensor are $100 \mathrm{~g}$ and $10 \mathrm{mV} / \mathrm{g}$, respectively, while the measure range and sensitivity of the displacement sensor are $50 \mathrm{~mm}$ and $0.1 \mu \mathrm{m}$.

3.2. Testing Procedure. Three earthquake records, namely, two real earthquake ground motion records (El-Centro record and Taft record) and one artificial earthquake ground motion record (Ninghe record), were applied in horizontal direction. The earthquake records were selected because the characteristic periods of the earthquake records are close to the different characteristic site periods prescribed by the Chinese seismic code [25] (Table 3). The acceleration timehistory curves of earthquake records are given in Figure 8.

Table 4 shows the loading process. The natural frequencies could be obtained through white noise scanning, and the accelerogram of the earthquake record was scaled in amplitude to $0.20 \mathrm{~g}, 0.30 \mathrm{~g}, 0.40 \mathrm{~g}, 0.50 \mathrm{~g}, 0.60 \mathrm{~g}, 0.70 \mathrm{~g}$, and $0.80 \mathrm{~g}$ to satisfy the test requirements. Considering that the

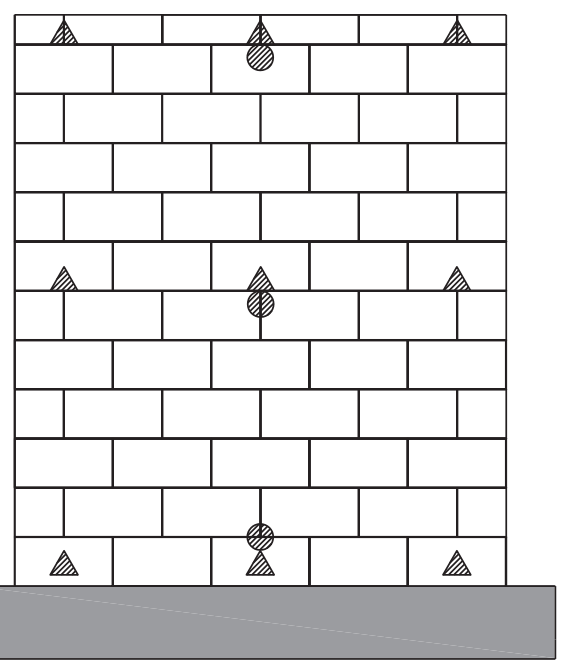

Acceleration sensor
Displacement sensor

FIGURE 7: Instrumentation arrangement. 
TABLE 3: Earthquake records and characteristic site period.

\begin{tabular}{lcccc}
\hline Earthquake & Direction & Time & Characteristic period (s) & Characteristic site period (s) \\
\hline Taft record & E-W & 1952.7 .21 & 0.44 & 0.40 \\
El-Centro record & N-S & 1940.5 .18 & 0.55 & 0.55 \\
Ninghe record & N-S & 1976.11 .15 & 0.90 & 0.75 \\
\hline
\end{tabular}

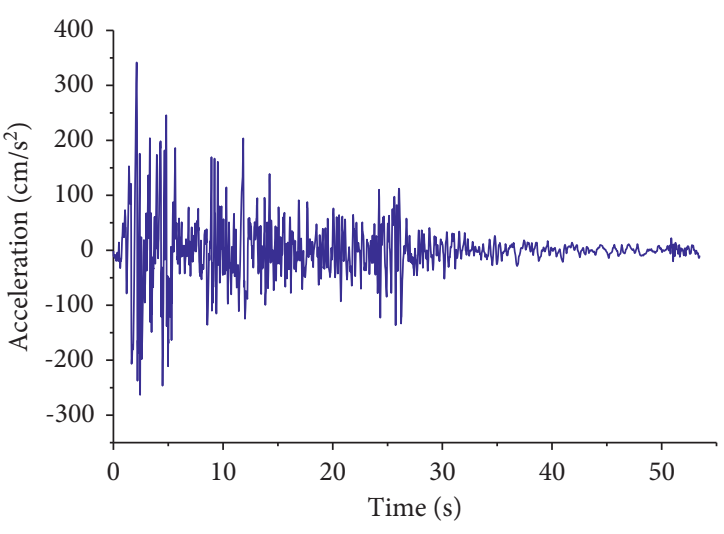

(a)

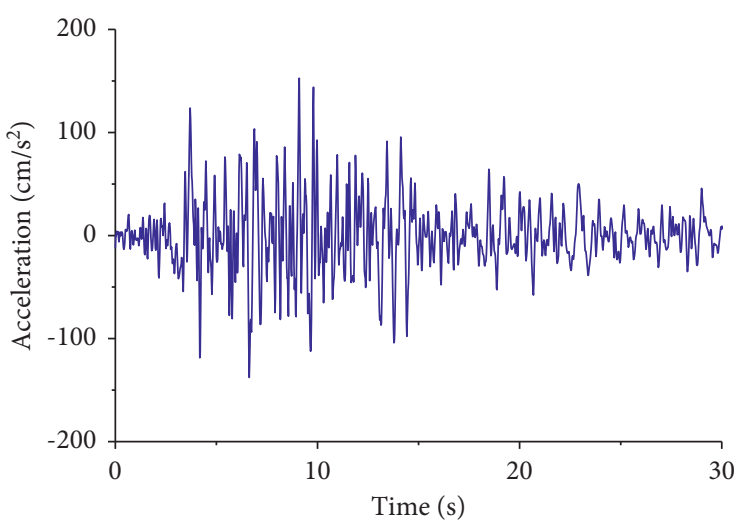

(b)

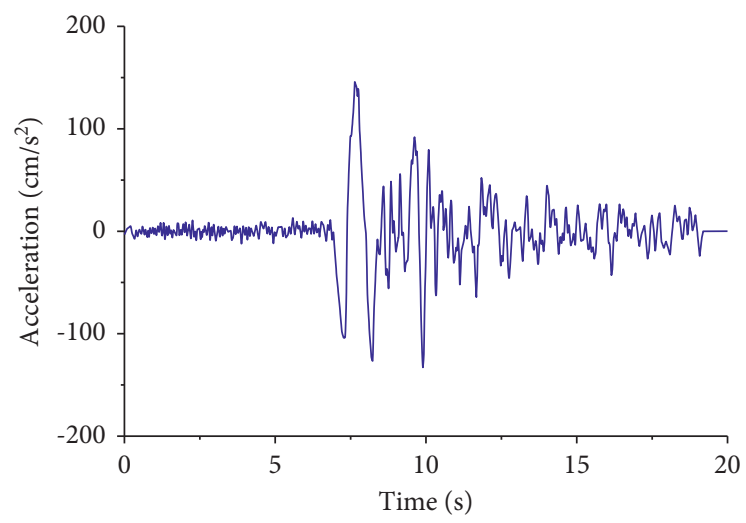

(c)

FIgURE 8: Acceleration time-history curves of earthquakes. (a) El-Centro record. (b) Taft record. (c) Ninghe record.

characteristic site period in a lot of cities of China is $0.55 \mathrm{~s}$, El-Centro record is selected for elastic-plastic analysis.

\section{Results and Discussion}

4.1. Experimental Observation and Failure Modes. The failure pattern of the specimens is described in Table 5. The cracks on the IDB wall and IDB wall boundaries were measured. It could be concluded that the crack usually appeared firstly at the bottom of the IDB wall, and as the PGA increased, cracks began to appear in the top corner of the specimen. The cracks mainly appeared at the joint of the IDB wall, ground beam, and shear wall, and there were basically no cracks in the interior of the IDB wall. During the loading process, there was no block crushing or block peeling from the specimen.

The crack length in the top corner of the specimen reduced from $1100 \mathrm{~mm}$ (AB0) to $670 \mathrm{~mm}$ (AB4-1), and the crack width decreased with the increase of the number of anchor bolts, meaning that the anchor bolt could effectively limit the development of cracks. Since the crack width and length of AB4-1 were smaller than AB4-2, it could be inferred that the arrangement mode had an influence on the out-of-plane mechanical performance of the IDB wall.

4.2. Frequency of Specimens. The natural frequencies of specimens can be obtained through white noise scanning, as given in Figure 9. When the PGA was not more than $0.20 \mathrm{~g}$ ( $\mathrm{AB} 0$ and $\mathrm{AB} 2$ ) or $0.50 \mathrm{~g}$ (AB4-1 and $\mathrm{AB} 4-2)$, the change of natural frequencies of the specimens was small. As the PGA continued to increase, the natural frequencies of the four specimens began to decrease significantly. For instance, when the PGA was $0.8 \mathrm{~g}$, the decrease amplitude of the natural frequency of was $25.6 \%$ for $\mathrm{AB} 0,22.4 \%$ for $\mathrm{AB} 2$, $11.2 \%$ for $A B 4-1$, and $12.3 \%$ for AB4-2. The following could be concluded:

(1) The anchor bolts could effectively prevent the specimens from damage. That is for the reason that 
TABLE 4: Loading procedure.

\begin{tabular}{lcc}
\hline Number & Loading condition & PGA (g) \\
\hline 1 & White noise & 0.05 \\
2 & El-Centro wave & 0.05 \\
3 & Taft wave & 0.05 \\
4 & Ninghe wave & 0.05 \\
5 & White noise & 0.05 \\
6 & El-Centro wave & 0.10 \\
7 & Taft wave & 0.10 \\
8 & Ninghe wave & 0.10 \\
9 & White noise & 0.05 \\
10 & El-Centro wave & 0.15 \\
11 & El-Centro wave & 0.20 \\
12 & White noise & 0.05 \\
13 & El-Centro wave & 0.30 \\
14 & El-Centro wave & 0.40 \\
15 & El-Centro wave & 0.50 \\
16 & White noise & 0.05 \\
17 & El-Centro wave & 0.60 \\
18 & El-Centro wave & 0.70 \\
19 & El-Centro wave & 0.80 \\
20 & White noise & 0.05 \\
21 & Two consecutive EL-Centro waves & 0.80 \\
22 & White noise & 0.05 \\
\hline
\end{tabular}

TABLE 5: Test observations and failure pattern.

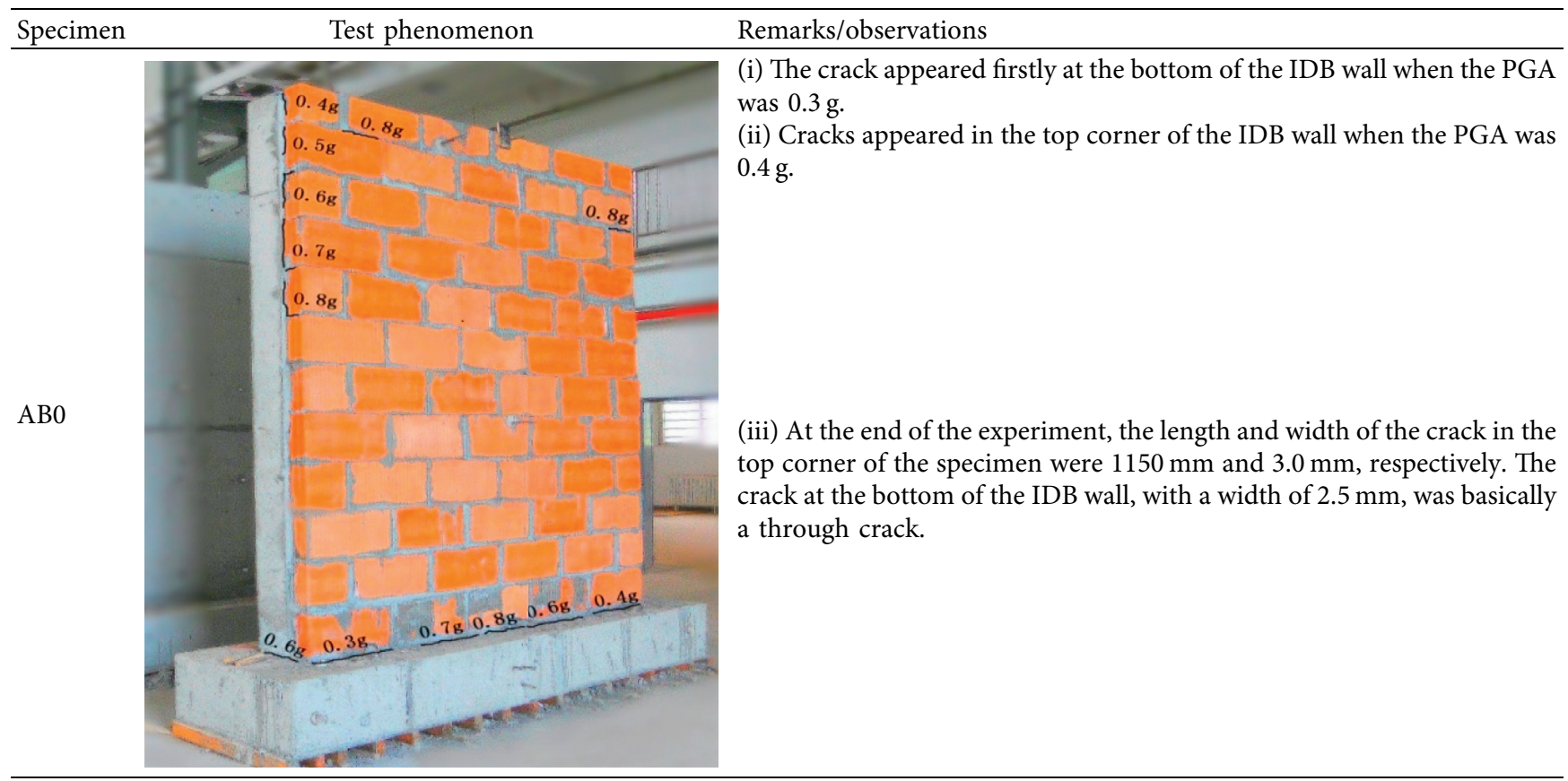


TABle 5: Continued.

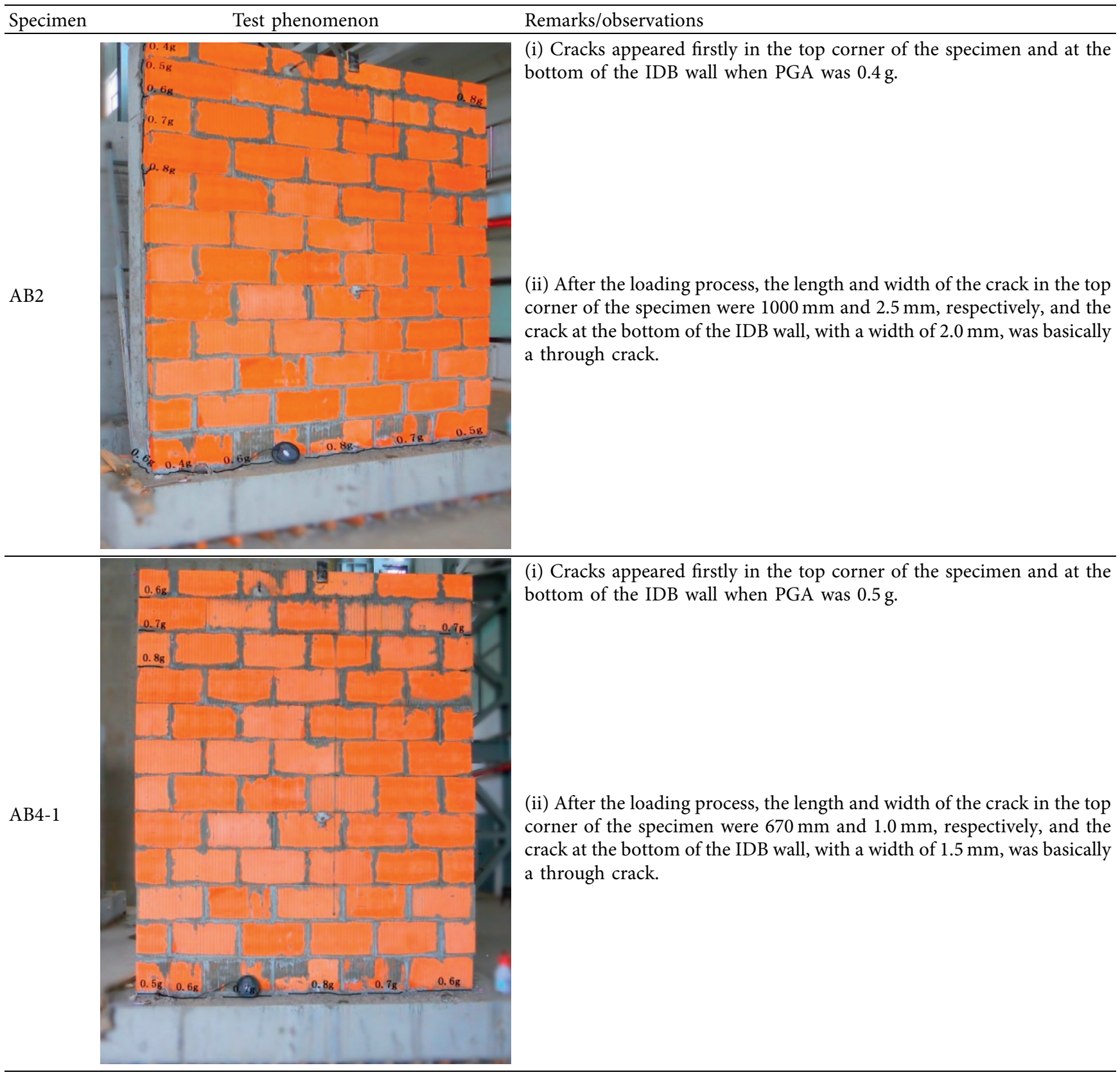


TABle 5: Continued.

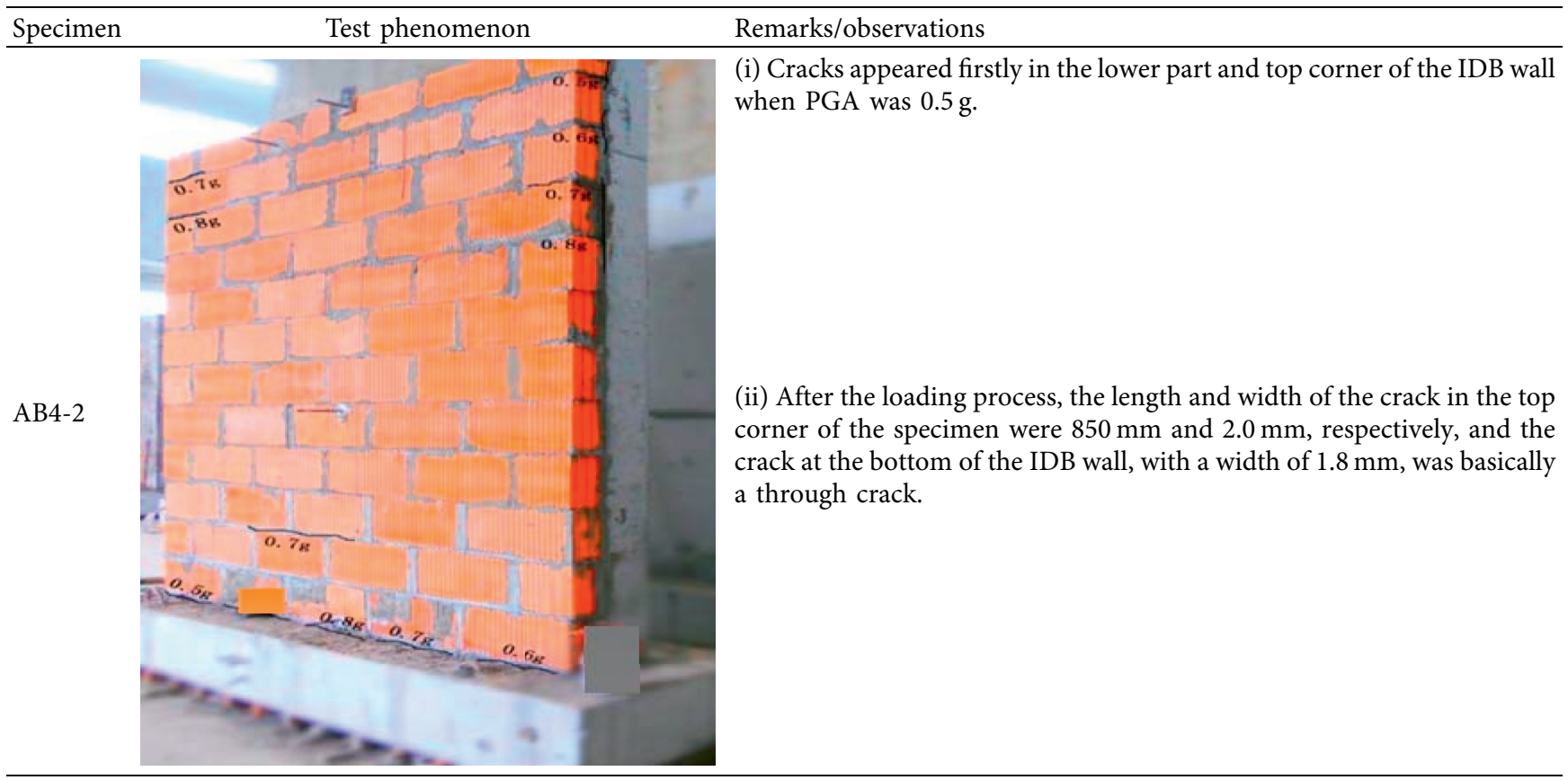

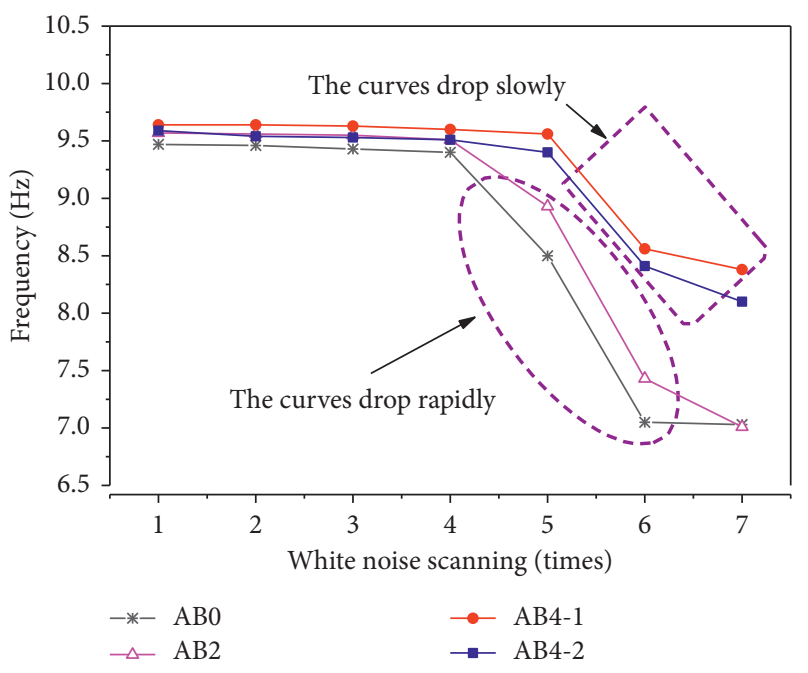

FIgURE 9: Natural frequency of the specimens.

the natural frequency of the specimen was related to the degree of damage; the more serious the damage, the smaller the natural frequency.

(2) Although the number of the anchor bolts was the same, the reduction amplitude of natural frequency of AB4-1 was smaller than that of AB4-2, meaning that arrangement mode of anchor bolts had an influence on preventing the structure failure.

4.3. Acceleration Response Analysis. The acceleration at the bottom of the IDB wall was basically the same as the input acceleration, so this paper only gives the peak acceleration in the middle-upper part of the IDB wall, as shown in Figure 10.

Although the cracks appeared and developed at the bottom of the IDB wall, the acceleration in the middle of the IDB wall increased linearly (Figure 10(a)), and the magnification coefficient of the acceleration response was about 1.3. The reason for these results could be that almost no cracks appeared between the IDB wall and shear wall, and the lower part of the specimens was still subjected to the outof-plane load as a whole. However, at the top of the specimens, the cracks mainly appeared between the IDB wall and the shear wall, causing the magnification coefficient of the acceleration response to increase suddenly (Figure 10(b)). 


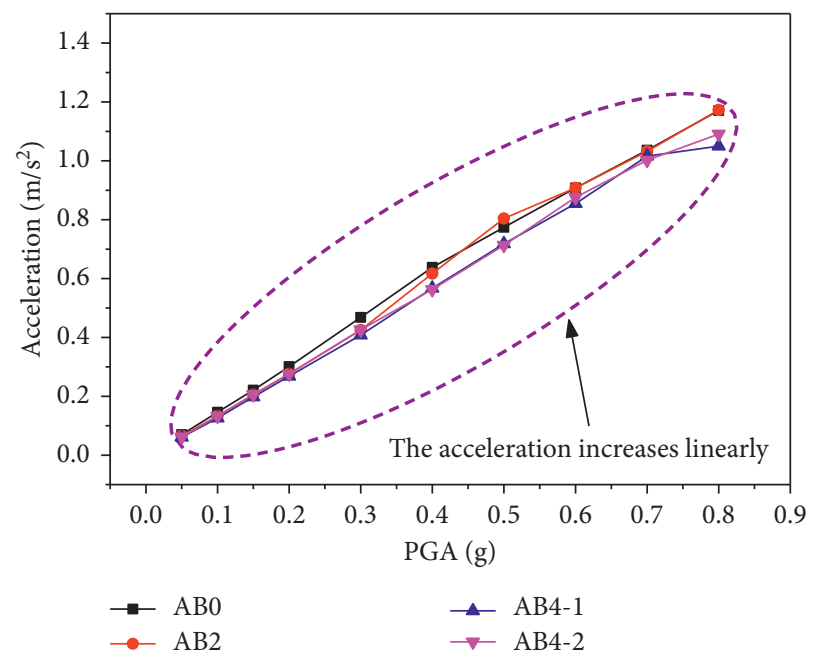

(a)

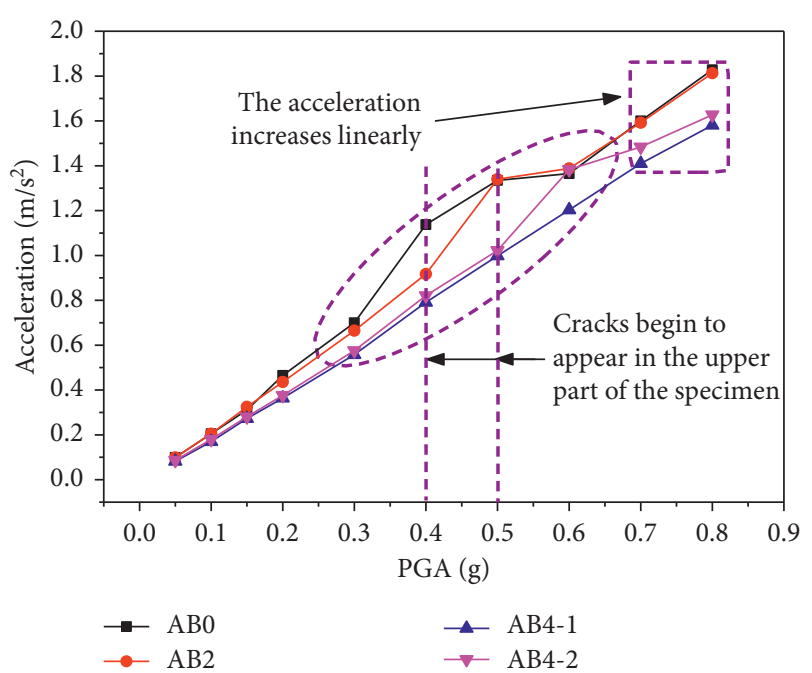

(b)

FIgURE 10: Peak acceleration of IDB wall at different positions. (a) In the middle of the IDB wall. (b) At the top of the IDB wall.

For instance, the acceleration at the top of $\mathrm{AB} 0$ increased linearly when the PGA was smaller than $0.4 \mathrm{~g}$. As the earthquake load increased, the cracks between the IDB wall and shear wall began to appear and develop, and the magnification coefficient of the acceleration response increased from 6.7 to 9.1 when the PGA was $0.40 \mathrm{~g}$ and from 9.1 to 11.1 when the PGA was $0.50 \mathrm{~g}$. It could also be concluded that when the crack width was small, it did not affect the global stress of the specimens. For instance, at the top of the AB4-1, the maximum width of crack between IDB wall and shear wall was only $1.0 \mathrm{~mm}$, and the acceleration increased linearly all the time during the loading process.

4.4. Displacement Response Analysis. In order to study the seismic performance of the IDB wall, the relative displacement and maximum displacement of the IDB walls are studied. The relative displacement is the difference between IDB wall and shear wall displacements, while the maximum displacement is the difference between the middle-upper and lower displacement of the IDB wall.

The relative displacements between IDB wall and shear wall are depicted in Figure 11. Since the relative displacement at the bottom of the specimen was small, only the relative displacement of the middle-upper part of the specimen was given in Figure 11.

In the middle of the specimen, it could be observed that although the maximum relative displacement was $0.96 \mathrm{~mm}$, no visible cracks appeared (Table 4). For $\mathrm{AB} 0$ and $\mathrm{AB} 2$, the relative displacement increased linearly until cracks appeared at the top of the specimens, while for AB4-1 and AB4-2, the relative displacement increased linearly all the time, which was not affected by the cracks at the top of the specimen.

At the top of the specimen, the relative displacement could directly reflect the appearance and development of the cracks. Take $\mathrm{AB} 0$ as example; the crack appeared firstly when the PGA was $0.4 \mathrm{~g}$, after which the relative displacement increased rapidly with the development of the cracks.

The maximum displacements of IDB wall under different conditions of PGA are given in Figure 12. From Figure 12, it could be concluded that the displacements of $\mathrm{AB} 0$ and $\mathrm{AB} 2$ were affected by the cracking at the bottom of the specimens. Once the crack appeared at the bottom of $\mathrm{AB} 0$ and $\mathrm{AB} 2$, the displacement of the specimens would increase rapidly. While for AB4-1 and AB4-2, the displacement was basically linearly increasing.

Through the analysis of Figures 11 and 12, it could be inferred that the displacement response of the IDB wall was closely related to the appearance and development of the cracks. This phenomenon was more obvious in $\mathrm{AB} 0$ and $\mathrm{AB} 2$; the displacement or relative displacement would increase rapidly after the appearance and development of the cracks. However, for AB4-1 and AB4-2, the displacement response was basically linear.

\section{Structural Calculation and Recommendations}

5.1. Structural Calculation. Restricted by the experimental conditions, this paper only studied the out-of-plane seismic performance of IDB walls. However, in engineering practice, we should not ignore the wind load effect on the mechanical performance of brick veneer walls. Therefore, wind load and seismic load should be considered simultaneously in structural calculation.

5.1.1. Calculation of Seismic Action. According to Chinese code GB 50011-2010 [25], equivalent lateral-force method can be used to evaluate the seismic load caused by the gravity of nonstructural components. Thus, the seismic load of IDB walls could be calculated as follows: 


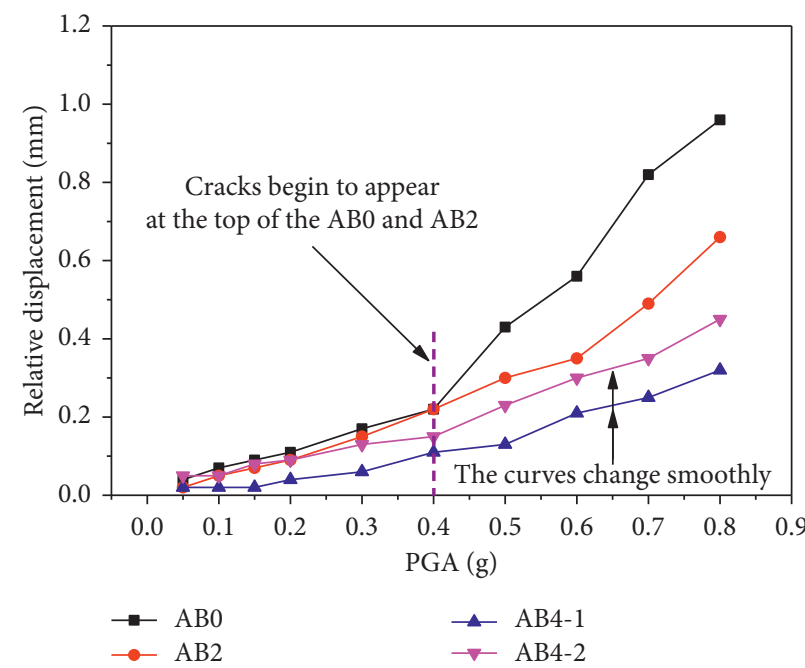

(a)

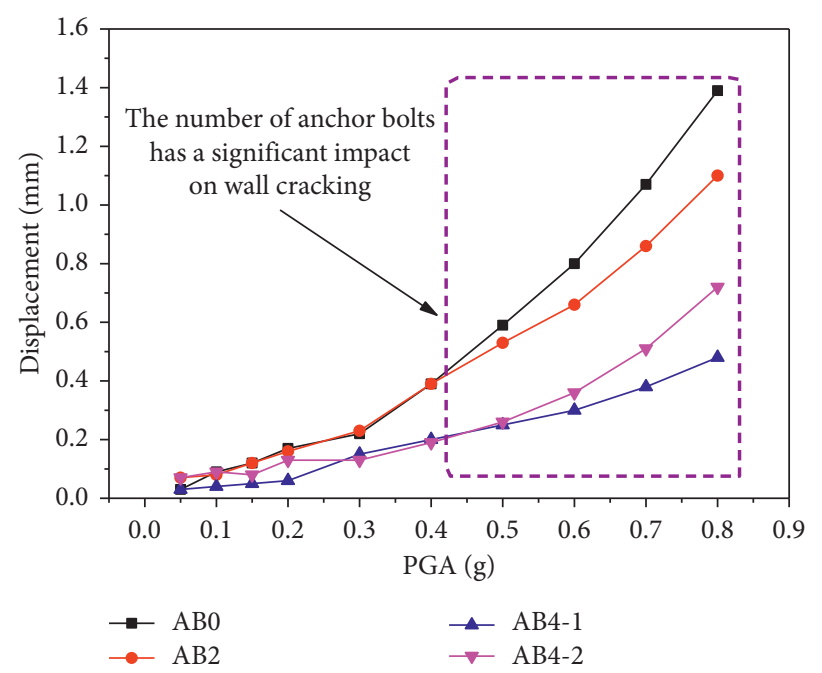

(b)

FIGURE 11: Relative displacement between IDB wall and shear wall. (a) In the middle of the specimen. (b) At the top of the specimen.

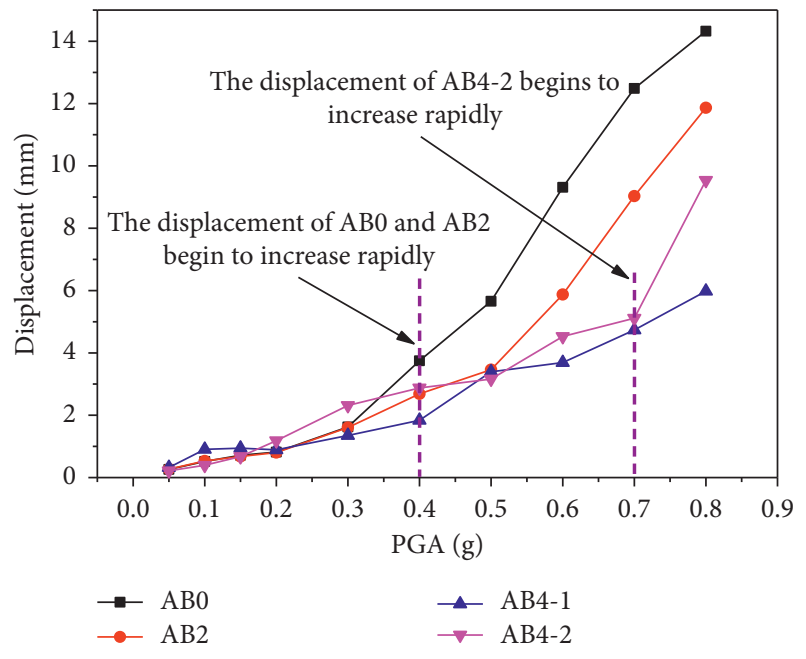

(a)

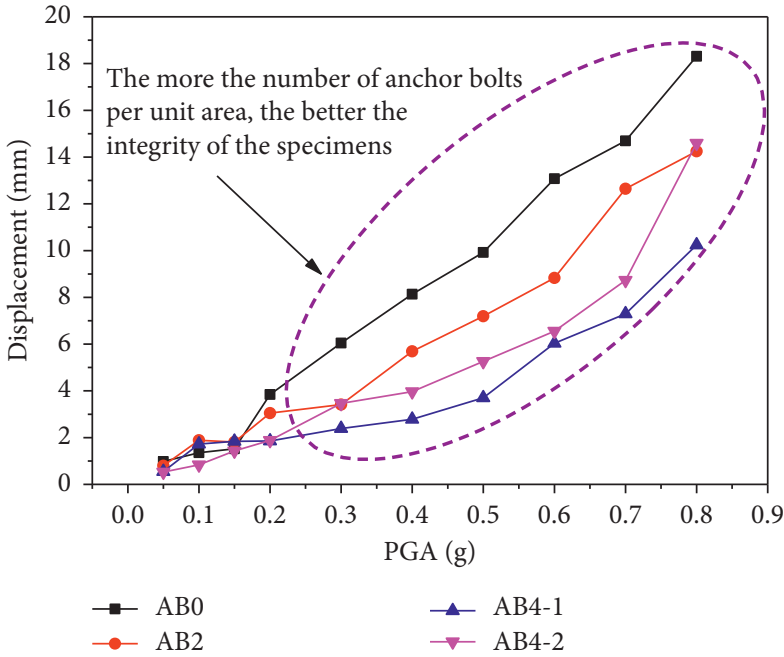

(b)

FIgURE 12: Displacement of IDB wall at different positions. (a) In the middle of the IDB wall. (b) At the top of the IDB wall.

$$
F=\gamma \eta \zeta_{1} \zeta_{2} \alpha_{\max } G,
$$

where $\gamma$ is the functional factor of the nonstructural components and equals $1.0 ; \eta$ is the type factor of the nonstructural components and equals $1.0 ; \zeta_{1}$ and $\zeta_{2}$ are the factor of state and location and equal 1.0 and 2.0, respectively; $\alpha_{\max }$ is the maximum value of seismic influence coefficient and equals 0.16 ; and $G$ is the gravity of nonstructural components (Table 6).

5.1.2. Calculation of Wind Load. The characteristic value of wind load is shown in the following equations [26]:

$$
\begin{aligned}
& w_{k}=\beta_{g z} \mu_{s l} \mu_{z} w_{0}, \\
& \beta_{g z}=0.80+1.60 \mu_{f}, \\
& \mu_{f}=0.5 \times 35^{1.8(\alpha-0.16)}\left(\frac{10}{z}\right)^{\alpha}, \\
& \mu_{z}=0.262\left(\frac{z}{10}\right)^{0.62},
\end{aligned}
$$

in which $\beta_{g z}$ is gust factor at height $z, \mu_{s l}$ is local shape coefficient, $\mu_{z}$ is wind pressure height coefficient, $w_{0}$ is basic 
TABLE 6: Gravity of IDB wall insulation system.

\begin{tabular}{lccc}
\hline & Mortar layer & IDB wall & Decoration layer \\
\hline Thickness $(\mathrm{mm})$ & 10 & 120 & - \\
Density $\left(\mathrm{kg} / \mathrm{m}^{3}\right)$ & 1500 & 500 & - \\
Gravity $\left(\mathrm{N} / \mathrm{m}^{2}\right)$ & 147 & 588 & 44 \\
Total gravity $\left(\mathrm{N} / \mathrm{m}^{2}\right)$ & & 779 & \\
\hline
\end{tabular}

TABle 7: The characteristic value of wind load at different heights.

\begin{tabular}{|c|c|c|c|c|c|c|c|}
\hline \multirow{2}{*}{ Height (m) } & \multirow{2}{*}{$\omega_{0}(\mathrm{kN} / \mathrm{m} 2)$} & \multirow{2}{*}{$\beta_{g z}$} & \multirow[b]{2}{*}{$\mu_{z}$} & \multicolumn{2}{|l|}{$\mu_{s l}$} & \multicolumn{2}{|c|}{$\omega_{k}(\mathrm{kN} / \mathrm{m} 2)$} \\
\hline & & & & Positive angle of buildings & Other locations & Positive angle of buildings & Other locations \\
\hline 20 & & 2.40 & 0.51 & & & 1.51 & 2.15 \\
\hline 50 & & 2.20 & 0.69 & & & 1.87 & 2.67 \\
\hline 80 & & 2.04 & 0.91 & & & 2.29 & 3.27 \\
\hline 100 & 080 & 1.98 & 1.04 & & 1 & 2.54 & 3.62 \\
\hline 150 & 0.88 & 1.87 & 1.33 & -2.0 & -1.4 & 3.06 & 4.38 \\
\hline 200 & & 1.79 & 1.58 & & & 3.48 & 4.98 \\
\hline 250 & & 1.74 & 1.81 & & & 3.88 & 5.54 \\
\hline 300 & & 1.70 & 2.02 & & & 4.23 & 6.04 \\
\hline
\end{tabular}

TABLE 8: The number of anchor bolts.

\begin{tabular}{lcc}
\hline Height $(\mathrm{m})$ & \multicolumn{2}{c}{ Number of anchors per square meter } \\
\hline$\leq 20$ & Positive angle of buildings & Other locations \\
\hline 20 & 2 & 4 \\
50 & 4 & 5 \\
80 & 4 & 6 \\
100 & 5 & 7 \\
150 & 6 & 8 \\
200 & 7 & 10 \\
250 & 8 & 11 \\
300 & 9 & 13 \\
\end{tabular}

wind pressure, $\mu_{f}$ is pulsation coefficient, and $\alpha$ is ground roughness index.

The wind load of maintenance structure for high-rise buildings is mainly wind suction, and the wind suction at the positive angle of buildings is larger than the wind suction at other locations [27]. The determination of coefficients in (2)-(5) is described in Table 7.

According to Chinese code GB 50009-2012 [26], the combination of earthquake and wind load can be expressed as

$$
S=\gamma_{Q_{1}} S_{Q_{1} k}+\gamma_{Q_{2}} \psi_{c} S_{Q_{2} k}
$$

Here, 1 and 2 represent wind and earthquake load, respectively; $S_{Q_{1} k}$ is load effect value calculated by $w_{k} ; S_{Q_{2} k}$ is load effect value calculated by $F ; \gamma_{Q_{1}}$ and $\gamma_{Q_{2}}$ are partial coefficients of load and equal 1.4 and 1.3, respectively; and $\psi_{c}$ is combination value coefficient and equals 0.6.

The formula for calculating the number of anchor bolts per unit area can be given as

$$
[n]=\alpha \gamma_{M} \frac{S}{k f_{t}},
$$

where $\alpha$ is the reduction factor considering the connection between mortar and IDB wall and equals $0.5, \gamma_{M}$ is the anchor connection importance coefficient and equals $1.1, k$ is the anchorage capacity reduction coefficient under earthquake and equals 0.7 , and $f_{t}$ is the design value of tensile bearing capacity of anchor bolts.

Based on (1)-(7), the number of anchor bolts to be arranged at different heights is shown in Table 8 . The results show that the number of anchor bolts in the test could meet the application requirements of IDB in high-rise buildings and has a good reference value.

5.2. Recommendations. According to the destruction features of the specimens during the test process, cracks mainly occurred at the bottom of the IDB wall and in the top corner of the specimen. When the PGA was small (0.3-0.5 g), cracks firstly appeared and developed between the IDB wall and ground beam, which was due to the bending effect of the specimens under the out-of-plane load. Premature cracks had a negative impact on the insulation effect of the IDB wall, so the bottom of the IDB wall needs to be effectively treated.

As the PGA increased, cracks began to appear between the IDB wall and the shear wall on both sides of the top of the specimens. Besides, the IDB walls were also subjected to wind loads in engineering application, and the suction in the 


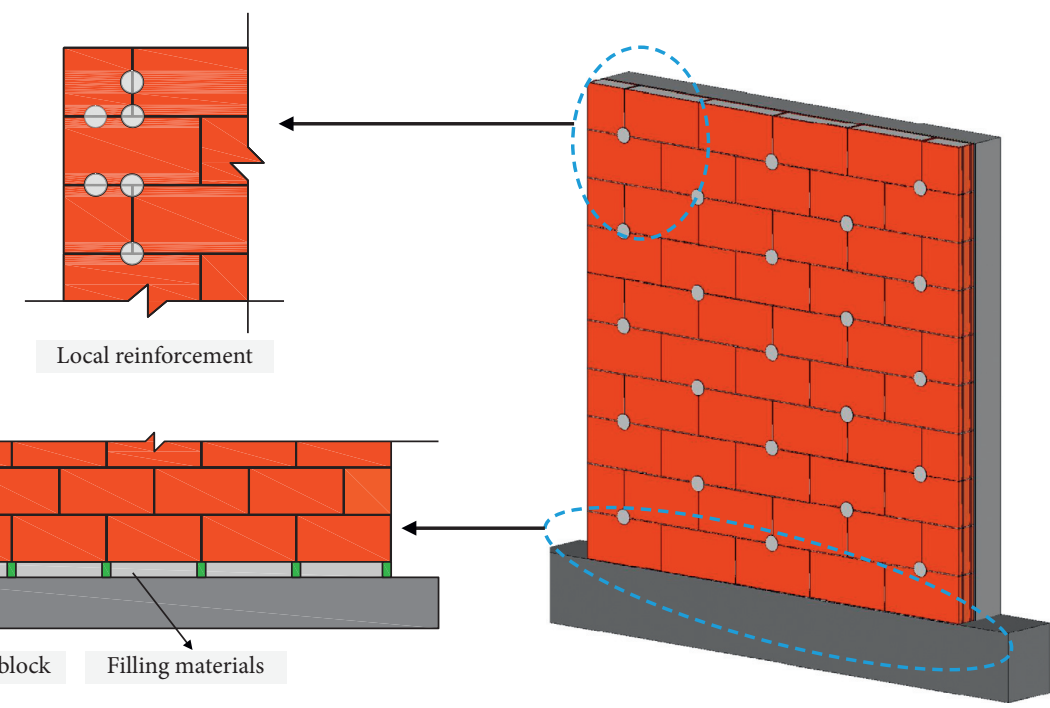

Figure 13: Design suggestion.

top corner, generated by negative wind pressure, was larger than that at other positions [27]; hence, attention should be paid to the reinforcement of the top corner in the structural design.

Thus, some recommendations are put forward in this paper, as shown in Figure 13.

(1) In order to prevent the cracks at the bottom of the IDB wall from occurring too early under the action of bending, cushion blocks with certain deformation ability, such as rubber block or wooden block, should be used to bear the dead weight of the IDB wall. Foaming agent can be used as filling materials to improve the insulation performance of IDB wall.

(2) In order to prevent cracks in the top corner of the wall from affecting the thermal insulation performance of the IDB wall, more anchor bolts should be used to strengthen the bonding between the IDB wall and shear wall at this location.

\section{Conclusions}

Shaking table tests are carried out on four specimens to investigate the out-of-plane performance of IDB walls. Failure mechanisms, frequencies, acceleration, and displacement (relative displacement) are evaluated, and the performance of anchorage mode is examined. The calculation formula of the number of anchor bolts and design suggestions are also given based on the experimental phenomena, so as to promote the application of IDB in engineering. The results obtained from the tests are briefly summarized as below:

(1) Appearance and development of cracks between the IDB wall and shear wall are obviously affected by the number of the anchor bolts. The larger the number of anchor bolts, the smaller the seismic load at the time of crack appearance, the shorter the crack length, and the smaller the crack width.

(2) The anchor bolts could obviously improve the outof-plane mechanical performance of IDB walls. Take $\mathrm{AB} 0$ and $\mathrm{AB} 2$ as example; when the seismic action is the same, the natural frequency of AB2 is larger, and the acceleration and displacement (relative displacement) are smaller.

(3) Although the number of anchor bolts is the same, the displacement (relative displacement) and acceleration of AB4-1 are smaller than those of AB4-2, showing that the staggered pattern of the anchor bolts is a better arrangement method than rectangular arrangement.

(4) The positive angle of the buildings should be strengthened to reduce the damage of IDB walls, and the calculation formula of the number of anchor bolts could be applied in the process of design.

Based on the test results (acceleration, displacement, and failure mode) and structural calculation, the acceleration and displacement requirements of different types of buildings could be satisfied through adjusting the number and arrangement of anchor bolts. Therefore, the study of this paper could effectively promote the application of IDB.

Computational intelligence algorithms, such as monarch butterfly optimization (MBO) [28], neutrosophic optimization (NSO) [29], artificial bee colony (ABC) [30], and ant colony algorithm (ACA) [31], are gradually used to analyze the seismic response of the structures, so as to optimize the structural design and improve the seismic performance of structures. However, the impact of these intelligent algorithms has not been considered in the specification; thus, considering the engineering application of IDB, the structural analysis method used in this paper is specified by Chinese code GB 50011-2010 [25]. Considering the optimal design of structures, the 
intelligent algorithms will be used to analyze the seismic performance of structures with IDB walls in subsequent studies.

\section{Data Availability}

The data that support the findings of this study are available on request from the corresponding author.

\section{Conflicts of Interest}

The authors declare that they do not have any commercial or associative interest that represents conflicts of interest in connection with the work submitted.

\section{Acknowledgments}

This research was supported by the Natural Science Foundation of Shaanxi Province (2021JQ-876) and Scientific Research Foundation for High-Level Talents (XJ17T08). The authors would like to thank Shaanxi Key Laboratory of Safety and Durability of Concrete Structures for the project testing.

\section{References}

[1] L. Fang, "Problems in building energy saving and application of energy saving construction technology," Construction Material Decoration, no. 38, pp. 41-42, 2017, in Chinese.

[2] S. L. Yang, Experimental Research on Bonding Behavior between XPS Insulation Board Layer and Structure Layer, Master thesis, Wuhan University of Technology, Wuhan, China, 2011.

[3] J. H. Crandell, "Below-ground performance of rigid polystyrene foam insulation: review of effective thermal resistivity values used in ASCE standard 32-01-design and construction of frost-protected shallow foundations," Journal of Cold Regions Engineering, vol. 24, no. 2, pp. 35-53, 2010.

[4] T. Mcfadden, "Thermal performance degradation of wet insulations in cold regions," Journal of Cold Regions Engineering, vol. 2, no. 1, pp. 25-34, 1988.

[5] M. Kehrer, H. Kuenzel, and K. Sedlbauer, "Ecological insulation materials-does sorption moisture affect their insulation performance?" Journal of Thermal Envelope and Building Science, vol. 26, no. 3, pp. 207-212, 2002.

[6] L. Wang, C. Wang, P. Liu, Z. Jing, X. Ge, and Y. Jiang, "The flame resistance properties of expandable polystyrene foams coated with a cheap and effective barrier layer," Construction and Building Materials, vol. 176, pp. 403-414, 2018.

[7] L. Jiang, D. Zhang, M. Li et al., "Pyrolytic behavior of waste extruded polystyrene and rigid polyurethane by multi kinetics methods and Py-GC/MS," Fuel, vol. 222, pp. 11-20, 2018.

[8] Y. Zhou, R. Bu, J. Gong, W. Yan, and C. Fan, "Experimental investigation on downward flame spread over rigid polyurethane and extruded polystyrene foams," Experimental Thermal and Fluid Science, vol. 92, pp. 346-352, 2018.

[9] A. A. Sayadi, J. V. Tapia, T. R. Neitzert, and G. C. Clifton, "Effects of expanded polystyrene (EPS) particles on fire resistance, thermal conductivity and compressive strength of foamed concrete," Construction and Building Materials, vol. 112, pp. 716-724, 2016.

[10] T. Masri, H. Ounis, L. Sedira, A. Kaci, and A. Benchabane, "Characterization of new composite material based on date palm leaflets and expanded polystyrene wastes," Construction and Building Materials, vol. 164, pp. 410-418, 2018.

[11] A. San-Antonio-González, M. D. R. Merino, C. V. Arrebola, and P. Villoria-Sáez, "Lightweight material made with gypsum and extruded polystyrene waste with enhanced thermal behaviour," Construction and Building Materials, vol. 93, pp. 57-63, 2015.

[12] S. Ramakrishnan, X. Wang, J. Sanjayan, and J. Wilson, "Thermal performance assessment of phase change material integrated cementitious composites in buildings: experimental and numerical approach," Applied Energy, vol. 207, pp. 654-664, 2017.

[13] Gb/T 30595-2014(Code of China), External thermal Insulation Composite Systems Based on Extruded Polystyrene, China Architecture and Building Press, Beijing, China, 2014, in Chinese.

[14] Db21/T 1271-2003(Code of China), Technical Specification for Exterior wall Outer thermal Insulation Based on EPS Board, China Architecture and Building Press, Beijing, China, 2003, in Chinese.

[15] Db34/T 5078-2017(Code of China), Technical Specification for Application of Expanded Perlite Insulation Board Thermal Insulation Project on Building, Anhui Engineering Construction Standard Design Office, Hefei, China, 2017, in Chinese.

[16] K. S. Al-Jabri, A. W. Hago, A. S. Al-Nuaimi, and A. H. AlSaidy, "Concrete blocks for thermal insulation in hot climate," Cement and Concrete Research, vol. 35, no. 8, pp. 1472-1479, 2005.

[17] J. Xamán, J. Cisneros-Carreño, I. Hernández-Pérez, I. Hernández-López, K. M. Aguilar-Castro, and E. V. MaciasMelo, "Thermal performance of a hollow block with/without insulating and reflective materials for roofing in Mexico," Applied Thermal Engineering, vol. 123, pp. 243-255, 2017.

[18] E. Fraile-Garcia, J. Ferreiro-Cabello, M. Mendivil-Giro, and A. S. Vicente-Navarro, "Thermal behaviour of hollow blocks and bricks made of concrete doped with waste tyre rubber," Construction and Building Materials, vol. 176, pp. 193-200, 2018.

[19] P. Mendonça, Habitar Sob uma Segunda Pele (in Portuguese), PhD thesis, University do Porto, Porto, Portugal, 2005.

[20] A. Martins, G. Vasconcelos, and A. Campos Costa, "Brick masonry veneer walls: an overview," Journal of Building Engineering, vol. 9, pp. 29-41, 2017.

[21] N. Desai and W. M. Mcginley, "A study of the out-of-plane performance of brick veneer wall systems in medium rise buildings under seismic loads," Engineering Structures, vol. 48, pp. 683-694, 2013.

[22] D. Reneckis, J. M. Lafave, and W. M. Clarke, "Out-of-plane performance of brick veneer walls on wood frame construction," Engineering Structures, vol. 26, no. 8, pp. 1027-1042, 2004.

[23] A. M. Memari, E. F. P. Burnett, and B. M. Kozy, "Seismic response of a new type of masonry tie used in brick veneer walls," Construction and Building Materials, vol. 16, no. 7, pp. 397-407, 2002.

[24] S. A. Marziale and E. A. Toubia, "Analysis of brick veneer on concrete masonry wall subjected to in-plane loads," Structures, vol. 2, pp. 1-7, 2013.

[25] GB 50011-2010(Code of China), Code for Seismic Design of Buildings, China Architecture and Building Press, Beijing, China, 2010, in Chinese. 
[26] GB 50009-2012(Code of China), Load Code for the Design of Building Structures, China Architecture and Building Press, Beijing, China, 2012, in Chinese.

[27] T. C. E. Ho, D. Surry, D. Morrish, and G. A. Kopp, “The UWO contribution to the NIST aerodynamic database for wind loads on low buildings: Part 1. archiving format and basic aerodynamic data," Journal of Wind Engineering and Industrial Aerodynamics, vol. 93, no. 1, pp. 1-30, 2005.

[28] O. Gardella, B. Crawford, R. Soto, J. Lemus-Romani, G. Astorga, and A. Salas-Fernández, "Bridges strengthening by conversion to tied-arch using monarch butterfly optimization," Advances in Intelligent Systems and Computing, vol. 1041, pp. 459-469, 2019.

[29] M. Sarkar and T. K. Roy, "Optimization of welded beam structure using neutrosophic optimization technique: a comparative study," International Journal of Fuzzy Systems, vol. 20 , no. 3, pp. 847-860, 2018.

[30] M. Yassami and P. Ashtari, "Using fuzzy genetic, artificial bee colony (ABC) and simple genetic algorithm for the stiffness optimization of steel frames with semi-rigid connections," KSCE Journal of Civil Engineering, vol. 19, no. 5, pp. 1366-1374, 2015.

[31] Y. B. Gong and Q. Y. Li, "Engineering structural optimization with an improved ant colony algorithm," in Proceedings of the 10th International Conference on Enhancement and Promotion of Computational Methods in Engineering and Science, pp. 1019-1024, Sanya, China, August 2006. 